Reactor Analysis

Division

Reactor Analysis

Division

Reactor Analysis

Division

Reactor Analysis Division

Reactor Analysis Division

Reactor Analysis Division

\title{
Material Degradation Analysis and Maintenance Decisions Based on Material Condition Monitoring During In-Service Inspections
}

Reactor Analysis

Division

Reactor Analysis by A. M. Yacout and Y. Orechwa

Division

Reactor Analysis

Division

Reactor Analysis

Division

Reactor Analysis

Division

Reactor Analysis

Division

RECEIVED

OCT 171996

OSTI

Reactor Analysis

Division

Reactor Analysis

Division

Reactor Analysis

Division

Reactor Analysis

Division

Reactor Analysis

Division

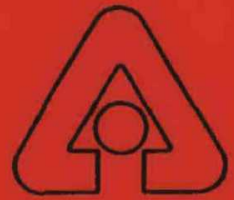

Argonne National Laboratory, Argonne, Illinois 60439

operated by The University of Chicago

for the United States Department of Energy under Contract W-31-109-Eng-38

Reactor Analysis

Division

Reactor Analysis

Division

Reactor Analysis

Division

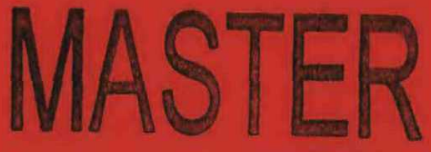

PDISTRIBUTION OF THIS DOCUMENT IS UNLMITED 
Argonne National Laboratory, with facilities in the states of Illinois and Idaho, is owned by the United States government, and operated by The University of Chicago under the provisions of a contract with the Department of Energy.

\section{DISCLAIMER}

This report was prepared as an account of work sponsored by an agency of the United States Government. Neither the United States Government nor any agency thereof, nor any of their employees, makes any warranty, express or implied, or assumes any legal liability or responsibility for the accuracy, completeness, or usefulness of any information, apparatus, product, or process disclosed, or represents that its use would not infringe privately owned rights. Reference herein to any specific commercial product, process, or service by trade name, trademark, manufacturer, or otherwise, does not necessarily constitute or imply its endorsement, recommendation, or favoring by the United States Government or any agency thereof. The views and opinions of authors expressed herein do not necessarily state or reflect those of the United States Government or any agency thereof. 


\section{DISCLAIMER}

Portions of this document may be illegible in electronic image products. Images are produced from the best available original document. 


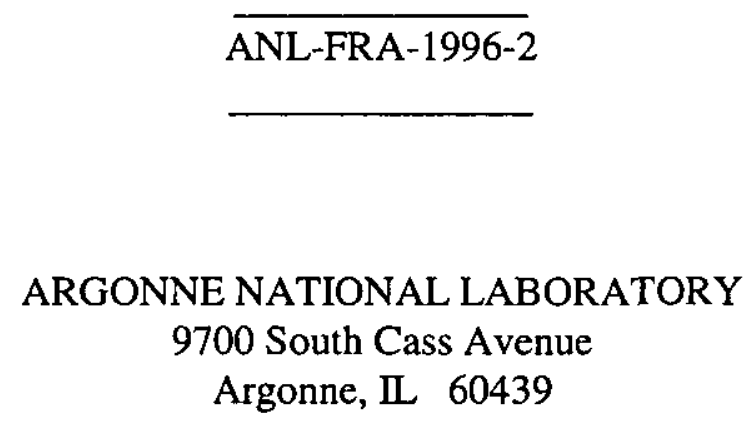

MATERIAL DEGRADATION ANALYSIS AND MAINTENANCE DECISIONS BASED ON MATERIAL CONDITION MONITORING DURING IN-SERVICE INSPECTIONS

by

A. M. Yacout and Y. Orechwa

Reactor Analysis Division

March 1996

Results reported in the FRA series of memoranda frequently are preliminary and subject to revision. Consequently they should not be quoted or referenced without the authors' permission

Work supported by

U.S. Department of Energy

Nuclear Energy Programs 
$$
\text { . }
$$ 
I. INTRODUCTION

III. ESTIMATION OF THE TIME TO EXCEED A FIXED LEVEL OF

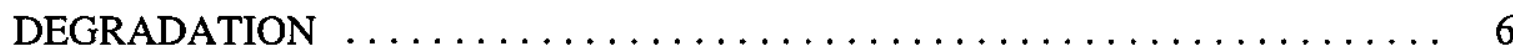

1. Estimation of the Probability Distributions and Their Confidence Intervals . . 7

2. Application to Cladding Deformation of Irradiated Reactor Fuel . . . . . . . 9

IV. DEGRADATION MODEL VERIFICATION $\ldots \ldots \ldots \ldots \ldots \ldots \ldots \ldots \ldots$

1. Feedforward Artificial Neural Networks $\ldots \ldots \ldots \ldots \ldots \ldots \ldots \ldots$

2. Backpropagation Algorithm $\ldots \ldots \ldots \ldots \ldots \ldots \ldots \ldots \ldots \ldots \ldots$

3. Application of an ANN to Degradation Analysis of Cladding in

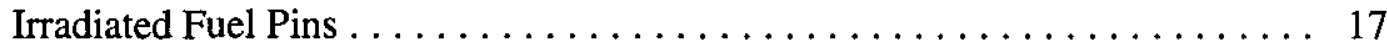

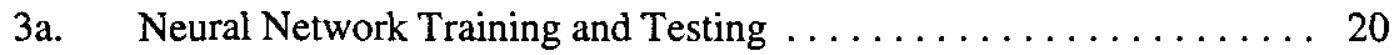

3a.1. The Neuralyst Program ................... 20

3a.2. Optimum Network Parameters and the Genetic Supervisor . . . 21

3b. ANN Estimates of the Degradation Data ............... 23

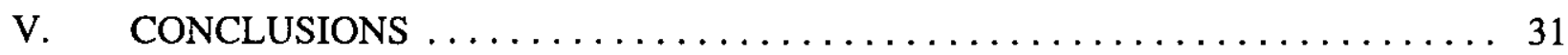

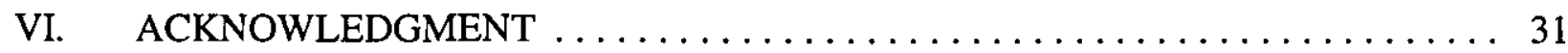

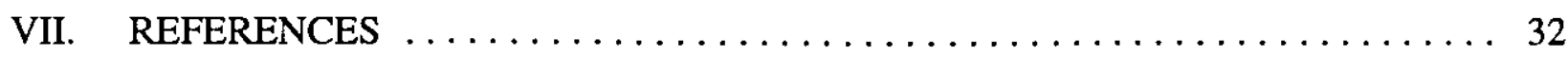


-iv- 


\section{LIST OF FIGURES}

Page

1. Schematic Scenario of Net Expected Revenue with Maintenance Costs:

Reduced Operating Levels $\left(\mathrm{C}_{0}\right)$, Replacement of Component $\left(\mathrm{C}_{\mathrm{R}}\right)$, and

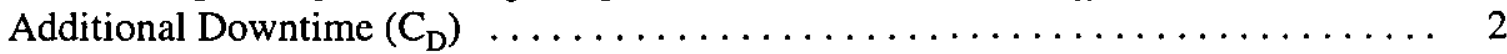

2. Decision Tree for the Schematic Scenario of Maintenance Costs ............ 4

3a. Schematic Degradation Paths for Individual Units $\ldots \ldots \ldots \ldots \ldots \ldots \ldots$

3b. Schematic Probability, with Confidence Interval, for Time to Exceed Proscribed

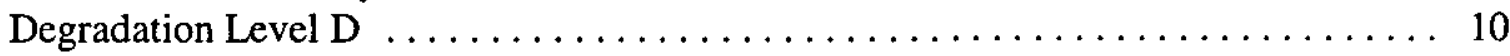

4. Degradation Paths for the Cladding of Two Irradiated Fuel Pins $\ldots \ldots \ldots \ldots \ldots .12$

5. Probability Distribution $\mathrm{P}\left(\mathrm{B} \leq \mathrm{b}_{\mathrm{o}} \mid \epsilon=1.0 \%\right)$, and Its Confidence Interval, for the Cladding of Irradiated Fuel Pins $\ldots \ldots \ldots \ldots \ldots \ldots \ldots \ldots \ldots \ldots \ldots$

6. Schematic Three Layer Neural Network $\ldots \ldots \ldots \ldots \ldots \ldots \ldots \ldots \ldots \ldots \ldots$

7. A Single Processing Unit in a Neural Network $\ldots \ldots \ldots \ldots \ldots \ldots \ldots \ldots \ldots$

8. Comparison of Measured Clad Strain to Regression Estimated Clad Strain ....... 19

9. Training and Testing Data Errors as a Function of the Number of Epochs $\ldots \ldots \ldots 22$

10. Comparison of Measured Clad Strain, Regression, and ANN Estimated Clad

Strain, as a Function of Axial Location (without ANN Genetic Optimization) . . . . 24

11a. Comparison of Measured Clad Strain, Regression, and ANN Estimated Strain, as a Function of Local Burnup for Pin T401 (without ANN Genetic Optimization) . . 25

11b. Comparison of Measured Clad Strain, Regression, and ANN Estimated Strain, as a Function of Local Burnup for Pin T414 (without ANN Genetic Optimization) . . 26

12a. Comparison of Measured Clad Strain, Regression, and ANN Estimated Clad Strain, as a Function of Axial Location (with ANN Genetic Optimization)

12b. Comparison of Measured Clad Strain, Regression, and ANN Estimated Strain, as a Function of Local Burnup for Pin T401 (with ANN Genetic Optimization)

12c. Comparison of Measured Clad Strain, Regression, and ANN Estimated Strain, as a Function of Local Burnup for Pin T414 (with ANN Genetic Optimization) . . . 30 


\section{LIST OF TABLE}

\section{Page}

I. Genetic Supervisor Optimized ANN Configuration $\ldots \ldots \ldots \ldots \ldots \ldots \ldots \ldots$ 


\title{
MATERIAL DEGRADATION ANALYSIS AND MAINTENANCE DECISIONS BASED ON MATERIAL CONDITION MONITORING DURING IN-SERVICE INSPECTION
}

\author{
by A. M. Yacout and Y. Orechwa
}

\begin{abstract}
The degradation of the material in critical components is shown to be an effective measure which can be used to compute the risk adjusted economic penalty associated with different maintenance decisions. The approach of estimating the probability, with confidence interval, of the time that a proscribed degradation level is exceeded is shown to be practical, as demonstrated in the analysis of irradiated fuel cladding. The methodology for the estimation of the probability is predicated on the existence of a parsimonious and robust mixedeffects model of the evolution of the degradation. This model, in general, relates measured surrogates of the degradation level to computed or measured variables, which characterize the environment during the operating history of the component. We propose and demonstrate the efficacy of using an artificial neural network, constructed via a genetic supervisor, as an aid in developing the requisite mixed-effects model and testing its continued validity as new data are obtained.
\end{abstract}


-viii- 


\section{EXECUTIVE SUMMARY}

Central to decision making in regard to maintenance or life extension of facilities is the estimate of the probability of the state of critical components at some future point in time, such as residual strength. This probability depends not only on the operating environment, but also on the variation in the composition and/or heat treatment of the material, which gives rise to a distribution of strength of any component around the nominal design strength. The operating parameters of a facility are set, at design, based on extensive laboratory testing and when possible on experience with comparable systems. When combined with a safety factor to cover the stochastic variability of the as-fabricated component, this generally results in highly reliable components; yet, because of the imperfect match between laboratory testing and operation, and some residual uncertainty, the performance of critical components, especially in new and innovative designs, is of sufficient concern to dictate in-service inspection programs. The purpose of the inspection program is to shed light on the future fitness for service of that particular component. The lack of statistically significant and relevant failure data, in these situations, precludes the traditional estimation of the time-to-failure probability.

Systematic measurement, during routine in-service inspections, via nondestructive analysis (NDA) techniques of surrogates for degradation, such as deformation or microstructural changes, for an ensemble of nominally identical components, however, allows estimation of a pseudo timeto-failure probability. This pseudo failure is associated with a proscribed level of degradation as quantified by its surrogate. The computation of such a probability estimate, together with its confidence interval, requires the construction of a database that relates the degradation measure to the history of the operating environment of the component. Modern computational hardware and validated software allow the rapid and reasonably precise quantification of the environmental variables that drive the degradation (such as, temperature, loads, neutron fluence, etc.). The values for these variables can be computed locally at the point of the degradation measurement. Thus, sequential measurements in time, of the degradation measure at a point on a particular component, can be used to define a sample degradation path. A set of such paths for an ensemble of nominally identical components forms the sample space for estimating the mixed-effects model that describes the degradation mode. This model is then the vehicle for the estimation of the probability that the proscribed level of degradation of some future particular component is not exceeded over some operating time.

This approach is tractable provided that two conditions are met:

1. A statistical mixed-effects model, that is robust and parsimonious, can be developed for the degradation mode on the basis of the preexisting test data for the ensemble of nominally identical components, and

2. The validity of the model can easily be tested as new measurements accumulate. That is, the degradation mode is stable in time.

These two issues can be addressed through the implementation of an Artificial Neural Network (ANN) with a genetic supervisor. The ANN has the advantage of being a nonparametric 
approach to modeling the degradation kinetics, while the genetic supervisor provides a computational process to select the architecture of the optimum network. We note that the ANN is a fixed-effects model, and, therefore, not amenable to the modeling of a set of degradation paths which is necessary for the estimation of the probability distribution of the time to failure. The determination of an appropriate ANN, however, does define the critical variables which determine the kinetics of the degradation mode. These variables are then used in the construction of the phenomenological mixed-effects model, which is the basis for the estimation of the time to failure distribution. By screening the set of independent variables via the genetic supervisor, the likelihood of attaining a robust and parsimonious mixed-effects model, with minimum trial and error testing, is greatly increased.

Since at issue are highly reliable components, the proposed methodology assumes progressive failures whose degradation modes are generally expected to be effective over the operating life time of the component. The ANN, therefore, can also act as a classifier of future measurements as to their consistency with the current model of the degradation mode. An indication that a different degradation mode has become significant (for example, the onset of tertiary creep) has significant implications on the extrapolation of the probabilities into the future. A change in the degradation mode requires a new model, which can be derived via the procedure described above.

We recapitulate the main points. The objective of the proposed methodology is to quantify the probability of future fitness for service of a particular critical component. A probability (in place of a point estimate ) is required to recognize the stochastic nature of as-fabricated components - they are not all identical, and it is known a-priori only that any particular component belongs to the class. This probability is critical to decision making with regard to maintenance or replacement of components before the end of life of the facility. The computation of this probability is predicated on the prior construction of a data base consisting of NDA measurements, made during in-service inspection, of degradation surrogates of these components, and of computed variables which characterize the history of the environment of components during operation. The database characterizes degradation paths. The ensemble of these paths forms a sample, which via the parametric bootstrap method gives an estimate of the probability of the time to failure in relation to a specified proscribed degradation level. To facilitate the construction of the requisite mixed-effects model of the degradation mode, the application of the artificial neural network with genetic supervisor is proposed. The ANN not only expedites the construction of the degradation model but also serves as a classifier to determine the relation of new data to the degradation model at hand. The genetic algorithm aids in the selection of the best architecture for the ANN, given the ensemble of test data. 


\section{INTRODUCTION}

Many new technological systems, especially those using advanced and innovative technologies to achieve improved economic performance, include components and structures that are designed with data collected under conditions not directly congruent with regard to the materials and operating parameters prevalent in the new design and its operation. The performance of some of these components may be critical to achieving the design lifetime at the expected operating conditions, and, thereby, reaping the anticipated economic rewards of the new design. Premature degradation of the materials in the critical components can incur considerable cost due to repair or premature replacement and a general loss of confidence in the new system; these can easily result in a net economic loss. This possibility of an economic loss dictates periodic inspection of the state of the materials. The aim of an inspection program is to facilitate operational decisions which will mitigate economic loss; for example, should the unit continue to operate as planned or should modifications in the unit or its operation be introduced. Conceptually, the link between the inspection (level of material degradation) and the operational decision (risk adjusted economic payback) is the estimate of the probability that at some future time a prespecified level of degradation is not exceeded, especially at the end of design life.

\section{A DECISION THEORETIC FRAMEWORK}

A heuristic illustration of a possible situation, in the operation of a power plant, for example, is given in Fig. 1. The figure shows schematically the expected net revenue from the operation of the plant as a function of time. The time axis is divided over the life of the plant into regular intervals, which have been defined at the design of the plant, and at which maintenance, refueling, in-service inspection, etc., are to take place. The premise of material condition monitoring is to determine, at the end of these intervals, the change and rate of change of microstructural or other degradation measures, as for example, in steel. It should be emphasized that it is not macroscale flaws, which often are precursors to imminent failure, that are at issue here. These would require immediate action. Rather, the information from material condition monitoring is amenable to aiding 


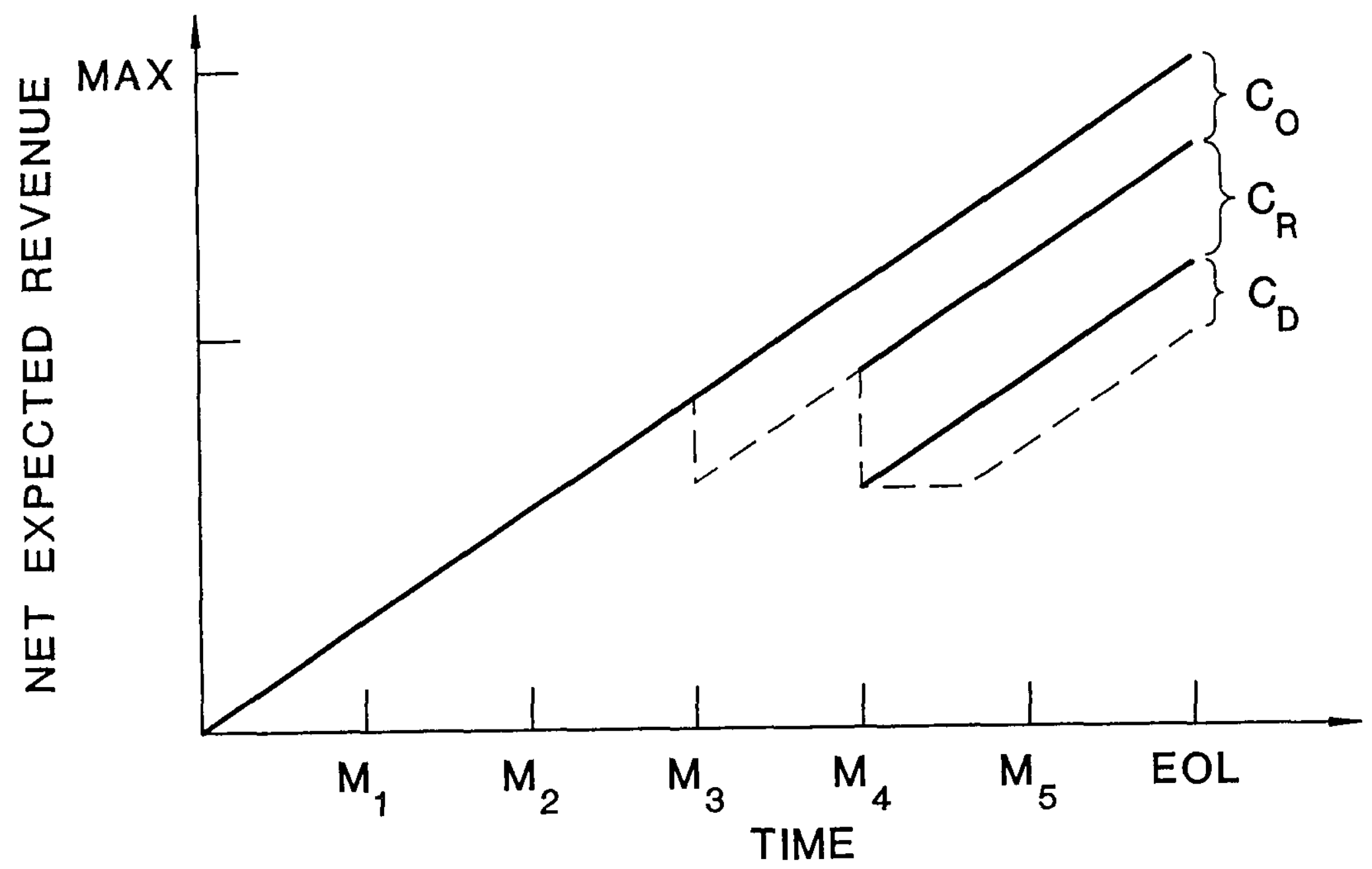

Fig. 1. Schematic Scenario of Net Expected Revenue with Maintenance Costs: Reduced Operating Levels $\left(C_{0}\right)$, Replacement of Component $\left(C_{R}\right)$, and Additional Downtime $\left(C_{D}\right)$ 
the decisions as to whether or not remedial action is warranted at the next scheduled maintenance or some other point before the end of life. ${ }^{1}$ The repair or replacement of major components generally requires significant lead time to assure a minimum down time of the facility. The associated risk adjusted costs are not easily taken into account at the design stage.

The operational decision process, such as to whether to pursue a particular policy, can be put into a decision theoretic framework.[1] Decision theory is no panacea, but it allows the decision maker to organize his information and assumptions in a coherent way. The decision taken will then be optimum in light of the information at hand; both objective and subjective. In this context, central to the evaluation of the risk adjusted economic payback of the various available operational options is the estimate of the future state of the system. For example, suppose in Fig. 1, at inspection $\mathbf{M}_{3}$, a level of degradation is projected at the next scheduled maintenance $\mathrm{M}_{4}$, which indicates an unacceptable economic risk with regard to meeting the end of life expected return, initially projected at the design of the plant. The plant operator at $\mathrm{M}_{3}$ is confronted with a series of questions; should the plant be operated over the next period in a way that will reduce the rate of degradation; during the next maintenance period, $\mathrm{M}_{4}$, should the component be replaced or repaired, or can normal operation continue; what is the expected revenue at the end of life of the plant after the replacement or repair of the degraded component.

The scenario presented in Fig. 1 is formulated in Fig. 2 in the form of a decision tree. The decision to be made at the $i-$ th maintenance period is, first of all, whether or not to reduce operating parameters, such as power level, for example, in order to preclude severe degradation before the next maintenance period. It is at the next, the $\mathrm{i}+1 \mathrm{st}$, maintenance period, that repair or replacement, based on the information from the i-th period, will take place. Of course, repair or replacement could (and might even be necessary at times) take place at the i-th period, however, at an increase in down time and the associated cost. Material condition monitoring is meant to avoid this latter eventuality.

${ }^{1}$ We note that this approach is especially applicable at the end of the design life of a system when the economic benefits of life extension are assessed. 


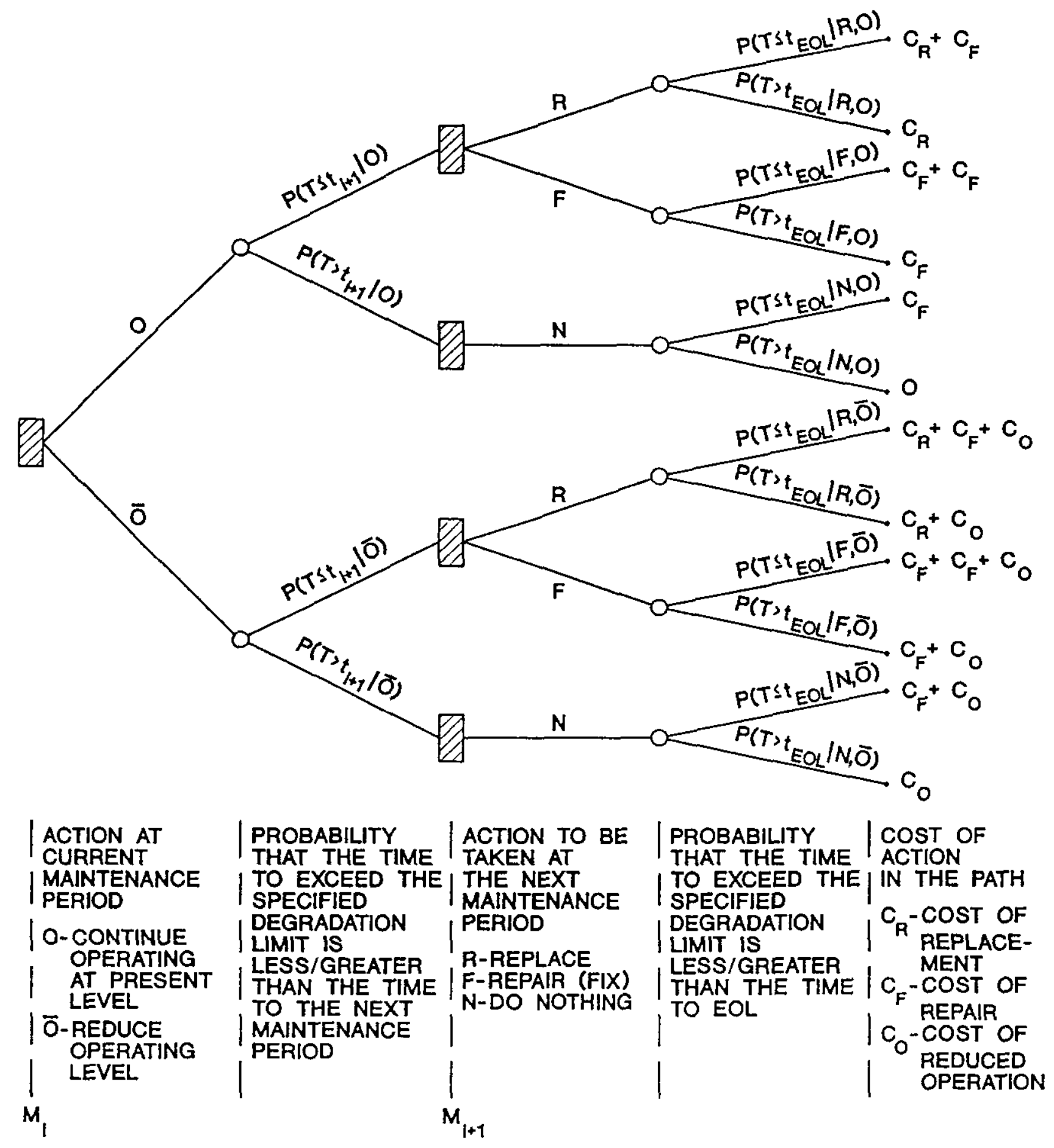

Fig. 2. Decision Tree for the Schematic Scenario of Maintenance Costs 
With each action in Fig. 2, such as the operation mode in the i-th maintenance period, or the replacement or repair of the component in the $\mathrm{i}+1 \mathrm{st}$, we can associate a cost. These are shown symbolically in Fig. 2 at the ends of the branches of the decision tree. These costs can be combined to give the total cost of a particular decision. A decision maker, however, assesses the different alternatives not on the basis of pure cost, but rather on the basis of the risk adjusted costs. For this, he needs an estimate of the uncertainty of the state of the component as a consequence of the action. The probability of the time to exceed the proscribed level of degradation describes this uncertainty.

The decision maker can then compute the expected cost of an action. For example, the expected cost of replacing the component, given that the system was operated under nominal conditions from the $\mathrm{i}-$ th to the $\mathrm{i}+1$ st maintenance period, and the component was replaced during the $\mathrm{i}+1$ st maintenance period, can be computed as

$$
E C(R \mid O)=P\left(T \leq t_{E O L} \mid R, O\right)\left[C_{R}+C_{F}\right]+P\left(T>t_{E O L} \mid R, O\right)\left[C_{R}\right]
$$

In this expression, the costs of replacing and repairing the component are given respectively by $C_{R}$ and $\mathrm{C}_{\mathrm{F}}$. The probability that the time to exceed the specified degradation limit is less than the remaining time to the end of the design life of the plant, given that the component has been replaced and the plant was operated under nominal conditions, is given by $P\left(T \leq t_{\mathrm{EOL}} \mid R, O\right)$. This is the probability that the replaced component will need to be repaired before the end of the design life of the plant. On the other hand, $\mathrm{P}\left(\mathrm{T}>\mathrm{t}_{\mathrm{EOL}} \mid \mathrm{R}, \mathrm{O}\right)$ is the probability that the time to exceed the specified degradation limit is greater than the end of design life of the plant, and, thus, the component will not need future repair. Analogous expressions, to Eq. (1) above, give the risk adjusted costs of the other actions under consideration, when making the decision at the $\mathrm{i}$-th maintenance period, as to how to proceed optimally.

The costs of replacing or repairing a component are generally well defined. In this report we focus on a methodology for estimating the less well defined, yet critical component of Eq. (1), the probability of the level of material degradation at a future time together with its confidence interval. The methodology is predicated on the estimation of a robust and parsimonious model for a particular 
degradation mechanism which leads to a potential failure mode. It is recognized that there is generally more than one possible mode which can lead to eventual failure. Thus, testing the validity of the model, for the data at hand, under the operating conditions, is critical for valid conclusions.

In addition to the scenario described in Fig. 1, many plant components do not have a specific design lifetime and are expected to survive for the design life of the plant as a whole. As such, they were not designed to be replaced or repaired at maintenance intervals. Premature degradation of such components may determine the useful life of the plant, and has significant economic implications. The premature degradation of such major components is, therefore, a major focus of material condition monitoring programs, and the associated estimation of the probability of exceeding a limiting level of degradation before the end of design life of the plant.

\section{ESTIMATION OF THE TIME TO EXCEED A FIXED LEVEL OF DEGRADATION}

The primary parameters which play a role in the deterioration kinetics of materials, such a steels, are generally difficult to measure during an inservice inspection. To overcome this shortcoming engineering practice has introduced various surrogates, especially those amenable to measurement with nondestructive techniques. Some advanced measurement techniques proposed for power plant components are:[2]

Positron Annihilation Doppler Analysis

SQUID Sensors

Magnetomechanical Acoustic Emission Method

Barkhausen Noise Method

Ultrasonic Methods 
These methods infer from the changes in electrical signals the changes in physical phenomena associated with material degradation in the component. The probability distribution of the time at which the degradation of the material in the component exceeds some specified level, to be useful in decision analysis, must be correlated with the properties of the material, its fabrication, the load to which it is subject, and other features of the operating environment, as for example, temperature and exposure to radiation and corrosive chemicals. In controlled experiments, these variables would be predetermined. Such a luxury does not exist when the source of the data is an operating plant. In that case, these variables are often measured, but more likely they are based on calculation. Modern thermal-hydraulic, structural, and neutronic computer codes allow good estimates of these variables. In addition, degradation is a monotonically increasing function of time; whereas the independent variables are likely to vary cyclically. It has previously been shown, in the context of degradation of irradiated fuel elements, that, in the case of temperature, an appropriate averaging method exists.[3] This method allows the averaging of slow cyclic variations in temperature, and is assumed to be extendable to other variables of interest in an analogous manner.

\section{Estimation of the Probability Distributions and Their Confidence Intervals}

It was shown previously that an effective method for estimating the probability of a level of degradation at some future time is via the application of the parametric bootstrap to a statistical mixed-effects model for a particular degradation mode.[4,5] Central to this model is the representation of a degradation path for each unit tested.[6] A unit, in the current context, need not necessarily be an individual entity, but rather a location on a large component, which is not strongly correlated to the degradation at other locations under consideration. The general form for such a model for the level of degradation $y_{i j}$ of the $i$-th unit at time $t_{j}$ can be written as

$$
y_{i j}=\eta\left(t_{j} \mid \underline{\varphi}, \underline{\theta}_{i}\right)+\epsilon_{i j}
$$

where

$$
\epsilon_{\mathrm{ij}} \sim \mathrm{N}\left(0, \sigma_{\epsilon}^{2}\right)
$$


and

$$
\mathrm{i}=1,2, \cdots, \mathrm{n} \text { and } \mathrm{j}=1,2, \cdots, \mathrm{m}_{\theta_{1}} \leq \mathrm{m} \text {. }
$$

The total number of inspections of the level of degradation of $\mathrm{n}$ units is $\mathrm{m}$, while the number of inspections of the $\mathrm{i}$-th unit is $\mathrm{m}_{\theta_{1}}$.

This model, in its general form, is a mixed-effects model. That is, it is dependent on both fixed and random parameters. In Eq. (2), the vector $\varphi$ represents the fixed-effects parameters; these are common to all units. For example, $\varphi$ can be a fixed temperature to which a set of units is exposed during testing. The vector $\underline{\theta}_{i}$ of random-effects parameters reflects characteristics which vary from unit to unit. The latter parameters, for example, take into account the comparatively large range of microstructures permitted by design specifications and the fact that trace compositions can often affect microstructure. These effects manifest themselves by inducing different levels of degradation for the same environmental conditions. The random variable $\epsilon_{\mathrm{ij}}$ represents the degradation measurement error at inspection time $t_{j}$ for unit $i$. The vector $\underline{\theta}_{i}$ of random effects parameters follows an unknown multivariate distribution $G_{\theta}\left({ }^{\cdot}\right)$. The assumption of the form of this distribution, and its estimation from the sample data, is a central part of this methodology.

In the model, as formulated in Eq. (2), the level of degradation $\mathrm{y}_{\mathrm{ij}}$ is a random variable. For applications in the context of the decision theoretic framework described in the pervious section, we wish to fix the level of degradation at some value beyond which the component is assumed to be no longer functional (i.e. "failed"). To this end, Eq. (2) can be reformulated to give

$$
P(T \leq t)=F_{T}\left(t \mid \varphi, G_{\theta}(\cdot), D, \eta\right)
$$

where time is now a random variable and $\mathrm{D}$ is the proscribed level of degradation. The prescription for estimating this probability, together with its confidence limits, have been described in Ref. 4, and in Ref. 5 by its application to irradiated fuel using reactor operating data. 
The procedure is briefly illustrated in Fig. 3. The degradation paths for each of the individual units are shown in Fig. 3a. These represent the fits of a parsimonious model of a degradation mode to the data, generally via nonlinear regression. Thus, each path, which gives the evolution of the degradation for a single unit, has unique values of the fitted parameters. The parameters are random variables, since they represent the unique characteristics of each unit. These parameters are the basis for the estimate of the multivariate distribution $G_{\theta}(\cdot)$ of the random parameters.

The point estimate of $\mathrm{P}(\mathrm{T} \leq \mathrm{tID})$ can then be computed by sampling the multivariate distribution $\mathrm{G}_{\theta}(\cdot)$ of the random parameters and generating a sufficiently large number of random sample paths. The proportion of sample paths intersecting the proscribed level of degradation represents an estimate of, $\mathrm{P}(\mathrm{T} \leq \mathrm{tID})$ and forms the estimate in Fig. $3 \mathrm{~b}$.

A point estimate is insufficient for assessing risk or making decisions under uncertainty. These require estimates of the confidence we can place in the point estimate based on sample information. A parametric bootstrap procedure is appropriate in this case for estimating the confidence intervals shown in Fig. $3 \mathrm{~b}$. This procedure, in essence, generates simulated degradation paths by sampling from the multivariate distribution $\mathrm{G}_{\theta}(\cdot)$ of random parameters estimated from the data, and the distribution $\mathrm{N}\left(0, \sigma_{\epsilon}^{2}\right)$ of measurement error. The bootstrap procedure, by generating $\mathrm{N}_{\mathrm{s}}$ sets of simulated degradation paths, allows $\mathrm{N}_{\mathrm{s}}$ estimates of $\mathrm{P}(\mathrm{T} \leq \mathrm{tID})$ to be computed. These $\mathrm{N}_{\mathrm{s}}$ estimates form their own distribution which is then used to define the percentile limits of the confidence interval.

\section{Application to Cladding Deformation of Irradiated Reactor Fuel}

A critical parameter in the optimization of a reactor core design is an estimate of the fuel pin lifetime under normal reactor operating conditions. This estimate becomes particularly important when a new fuel type is under consideration for which there is limited experience. An example of this is the HT-9 clad metallic fuel design for the core of the proposed Integral Fast Reactor. Degradation analysis is particularly germane in this case, for no failures have been observed under normal reactor operating conditions in similar pins at burnups up to 20 at.\%. 


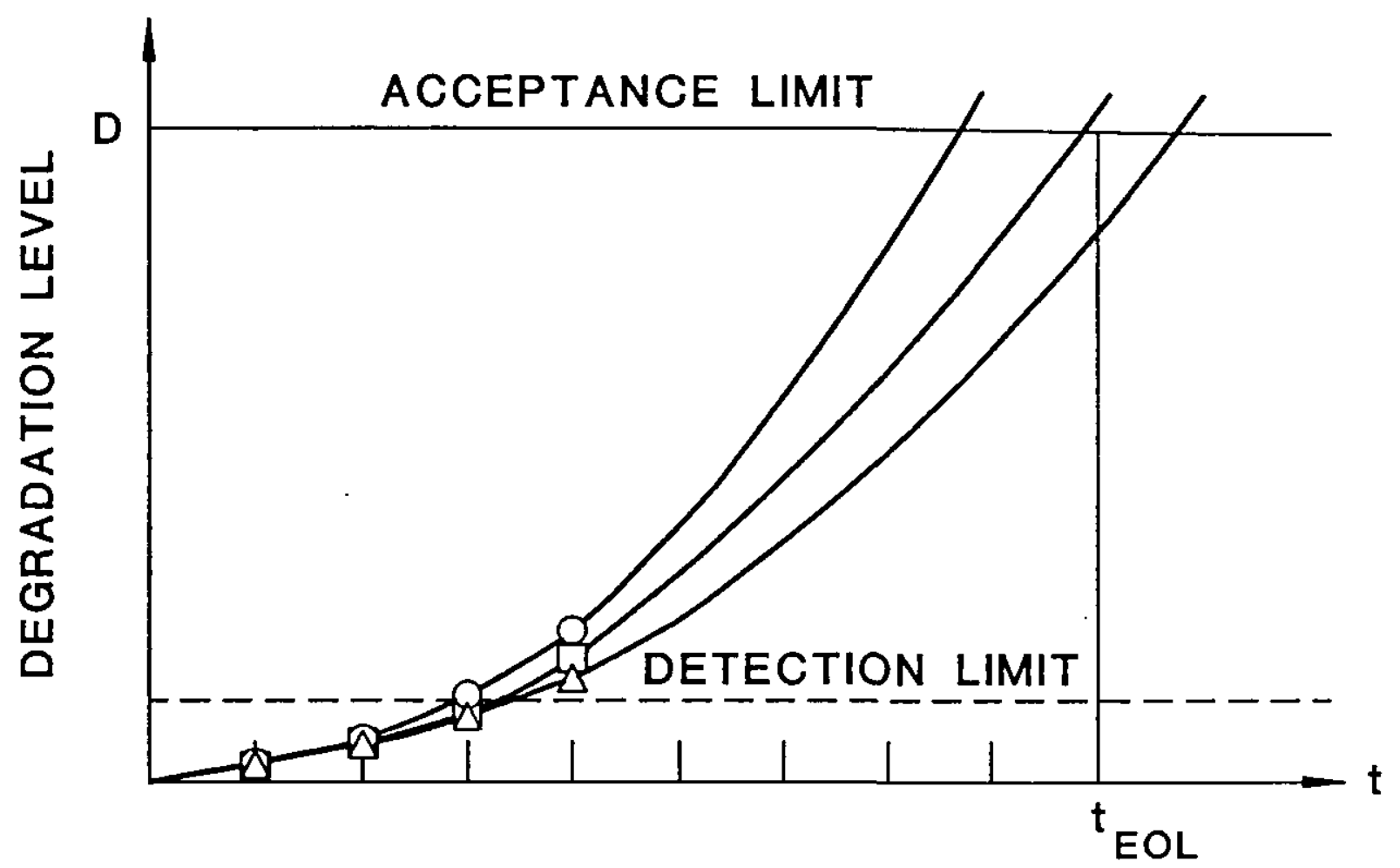

Fig. 3a. Schematic Degradation Paths for Individual Units

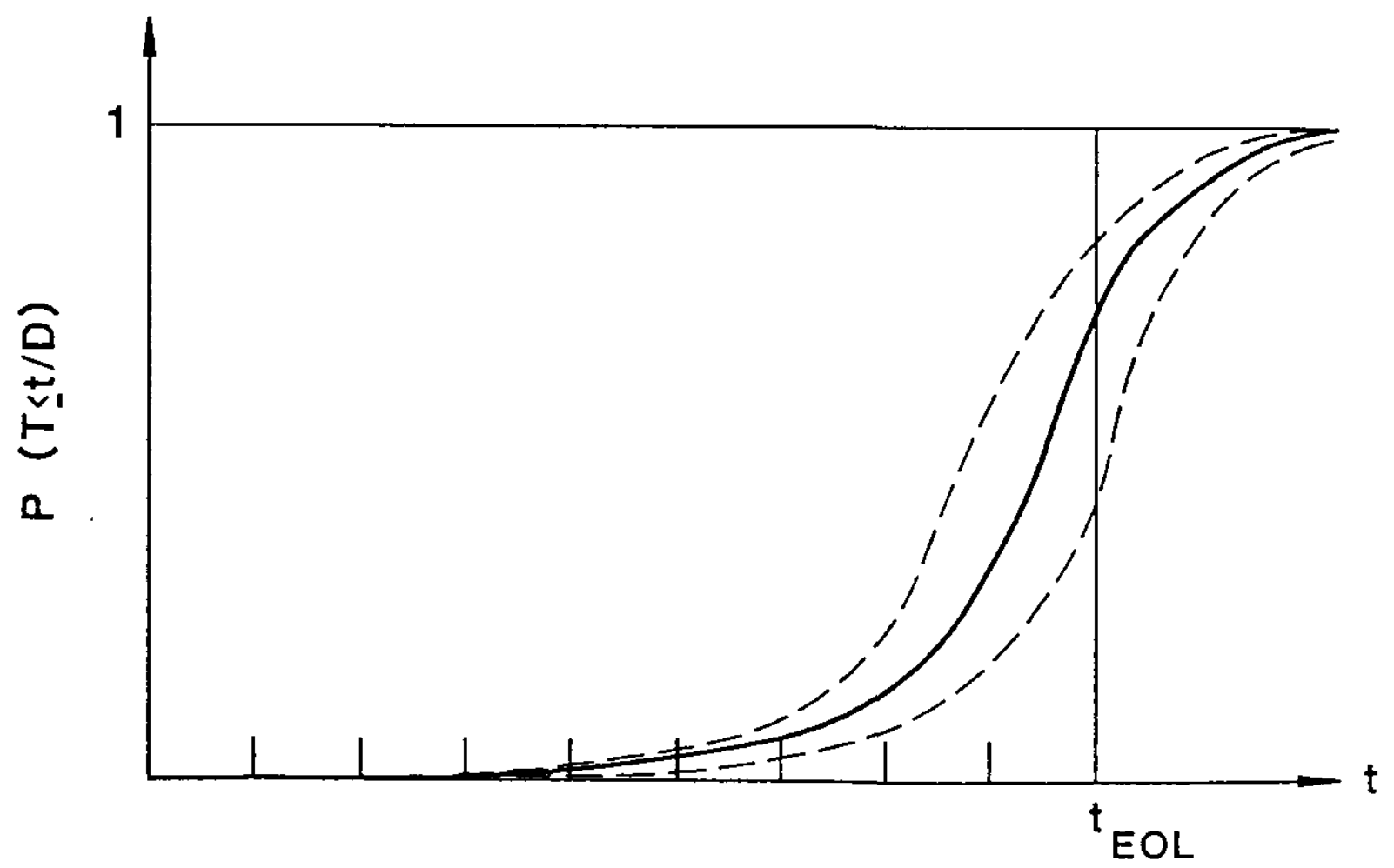

Fig. 3b. Schematic Probability, with Confidence Interval, for Time to Exceed Proscribed Degradation Level D 
For analysis, 19 pins were chosen from experiment X425 conducted in EBR-II. Of these, 16 pins were reconstituted four times, and three pins three times. At each reconstitution profilometry measurements were made of the cladding strain, which is representative of the pins' degradation. The degradation analysis requires that the cladding strain, the degradation measure in Ref. 5 in this case, be related to variables which represent the physical processes that govern the degradation kinetics. These variables are gas pressure, burnup, fast fluence, displacements per atom (dpa) in the cladding, dpa rate, power density, nuclide density, and flow and cladding temperature. Contemporary three-dimensional neutronic[7] and thermal-hydraulic[8] computational capabilities allow detailed axial pin-by-pin calculation of these parameters. Moreover, the very low aspect ratio of the pins allows the approximation that the axial segments, over which the parameters are averaged, behave independently. The division of the pin into axial segments maximizes the information available with regard to each pin (i.e., unit) by significantly increasing the number of observations available for statistical analysis.

The data and the fit of the degradation paths for two sample pins is illustrated in Fig. 4. In the figure the local burnup of the fuel is used as a more appropriate random variable for the probability distribution than the time. The procedure described above has been applied to the 19 irradiated fuel pins from experiment $\mathrm{X} 425$ to estimate the probability distribution, with confidence interval, for burnups at which a prespecified cladding strain is exceeded (see Ref. 5). The probability distribution for a diametral strain limit of $1 \%$, together with $80 \%$ confidence limits is shown in Fig. 5.

\section{DEGRADATION MODEL VERIFICATION}

The derivation of the requisite robust and parsimonious model, for fitting the degradation paths, as in the case of the irradiated fuel pins in the above analysis, is based on phenomenological arguments, and a very time consuming trial and error approach of repeated evaluations of fits by nonlinear regression. Here, we propose the application of an artificial neural network (ANN), with a genetic algorithm supervisor, as a more direct approach to the evaluation of the robustness of the 


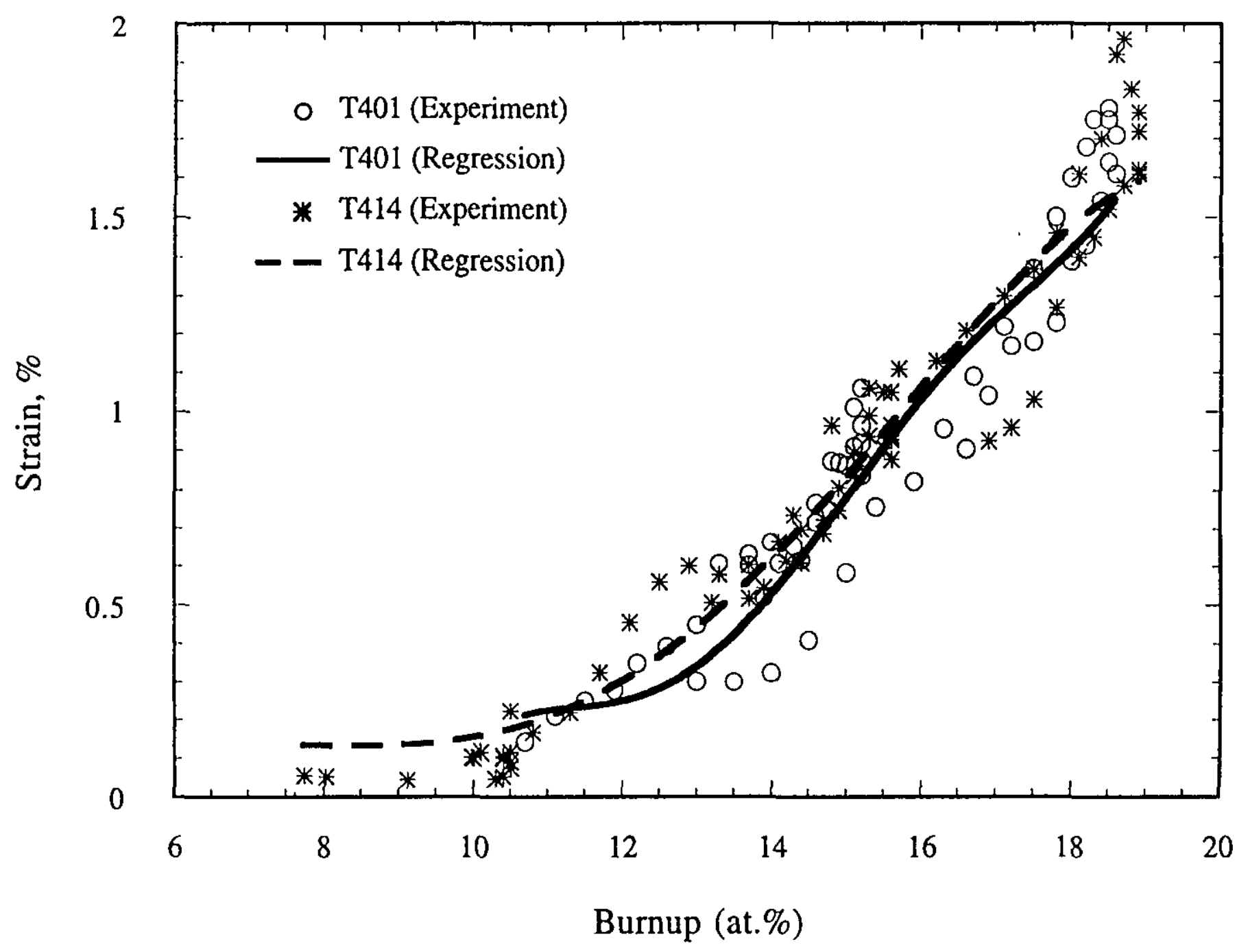

Fig. 4. Degradation Paths for the Cladding of Two Irradiated Fuel Pins 


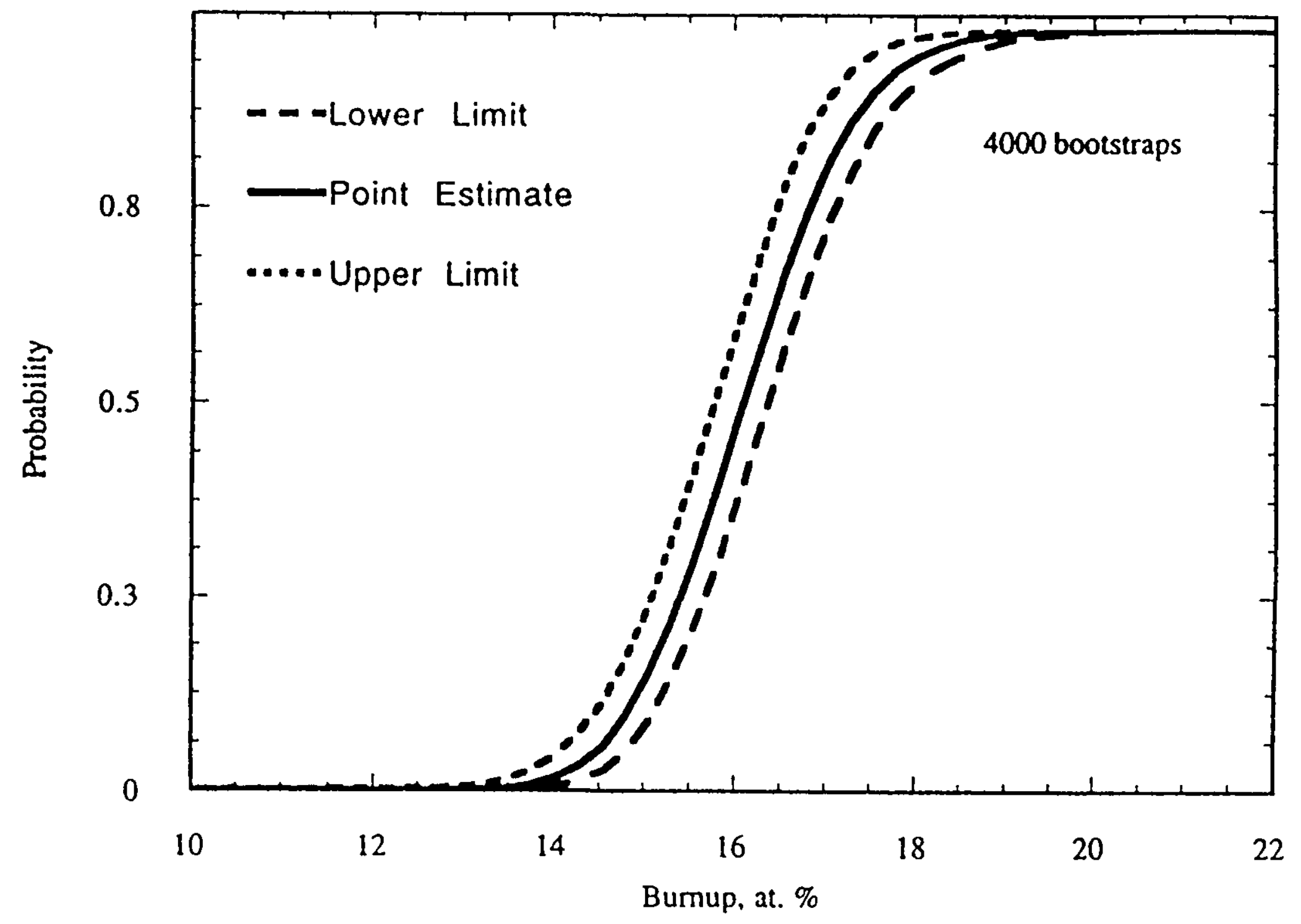

Fig. 5. Probability Distribution $\mathrm{P}\left(\mathrm{B} \leq \mathrm{b}_{\mathrm{o}} \mid \epsilon=1.0 \%\right)$, and Its Confidence Interval, for the Cladding of Irradiated Fuel Pins 
mixed effects model for the degradation. The power of the ANN lies in that it is model independent; and, in general, the drawback that it is dependent on a large set of fixed parameters, which are estimated via network training. This is directly the opposite of a parsimonious mixed effects model based on phenomenological physical arguments, whose distribution of parameters is central to the parametric bootstrap methodology.

Our approach is to assess the importance of the relevant independent variables germane to the problem with an ANN for the data on hand. The ANN is able to quantify the strength of the relation of each of the independent variables on the degradation measure, without explicit physical model assumptions. This, in principle, gives the reduced set of independent variables which needs to be considered in constructing the phenomenological model, and, thereby, significantly reduces the considerable effort via trial and error. The objective is to construct a phenomenological mixedeffects model on the basis of the reduced set of independent variables established with an ANN. As new data become available the ANN allows us to test whether this set of variables and the phenomenological model are still adequate for explaining the degradation path.

\section{Feedforward Artificial Neural Networks}

Artificial neural networks are mathematical models of brain-like systems which can be used in solving many computational problems.[9] The ANN is constructed from a set of basic processing units (neurons), each interacting with other units via excitatory or inhibitory connections. The most prevalent and generalized neural network architecture is the multilayer feedforward network, which consists of a set of neurons that are logically arranged into two or more layers where the information flows in one direction only. Figure 6 shows a typical three layered network structure with an input layer, a hidden layer, and an output layer of neurons. Each processing unit is characterized by an activity level $\eta$, an output value $y$, and a set of inputs $x$. A model of a single neuron, which consists of multiple inputs ( $\left.x^{\prime} \mathrm{s}\right)$ and one output $(y)$, is shown in Fig. 7. The neuron is characterized by weights $(\omega$ 's) that represents the strength of the connections from other units to this unit. The activation value for unit $i\left(\eta_{i}\right)$ is formulated as a linear 


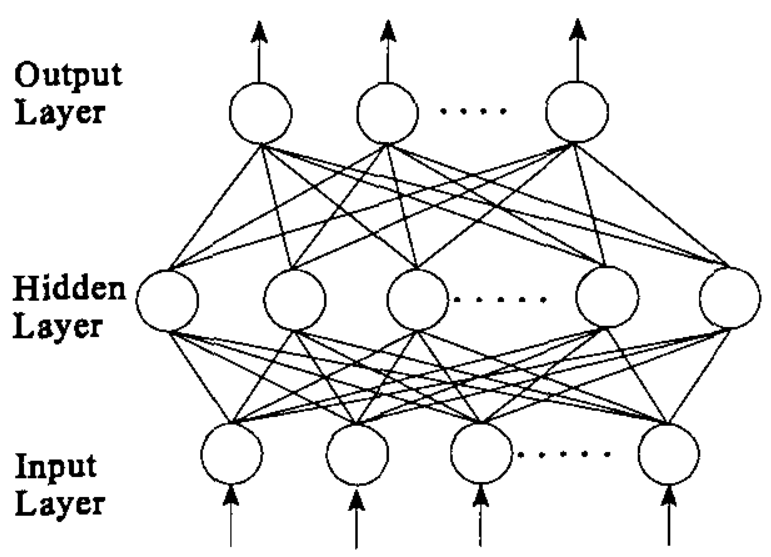

Fig. 6. Schematic Three Layer Neural Network

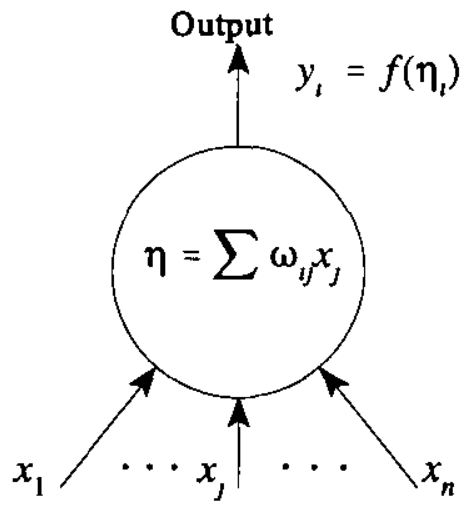

Fig. 7. A Single Processing Unit in a Neural Network 
combination of the inputs, weighted by the strength of the connections between the input and the neuron under consideration:

$$
\eta_{t}=\sum_{j} \omega_{i j} x_{j}
$$

The output of unit $i$ is a nonlinear function of its activation,

$$
\mathrm{y}_{\mathrm{i}}=\mathrm{f}_{\mathrm{i}}\left(\eta_{\mathrm{i}}\right)
$$

which is typically a sigmoid function given by

$$
f(\eta)=\frac{1}{1+\exp (-\eta)}
$$

The network training is based on using training data to adjust the connection weights in order to achieve a certain criteria, which is usually the minimization of the error in the network predictions. We note, that in designing the network architecture, no attempt is made to associate a physical meaning with the choice of either the activation function or the architecture. This contrasts sharply with the approach in the previous section, where a phenomenological model was constructed whose few parameters have a clear physical interpretation.

\section{Backpropagation Algorithm}

The backpropagation algorithm is a standard algorithm that has been used to train networks to solve a diverse array of problems.[10] The algorithm compares the computed output pattern to the desired output given by the data. Based on this difference, an error is computed for each output unit. The output-layer errors are propagated backwards through the network, where the error from the output layer is propagated to each node in the intermediate layer that contributed directly to the output. This process is repeated layer-by-layer by going toward the input layer. The connection weights are updated for each unit in a way that will drive the network towards a state which will 
minimize the training error. The basic equation which updates the weights from time (iteration) $t$ to time $(t+1)$ is given by

$$
\omega_{k j}(t+1)=\omega_{k j}(t)+\beta \delta_{p k}\left(x_{\imath}\right)_{p j}+\alpha \Delta_{p} \omega_{k j}(t-1)
$$

and is based on the familiar gradient descent algorithm, where $\beta$ is the learning rate and $\alpha$ is the momentum. In this equation, $\left(x_{t}\right)_{p j}$ refers to the input to the $j$-th unit due to the $p$-th layer, $\delta_{p k}$ is the error for the $k$-th unit, and $\Delta_{p} \omega$ is the weight change at the previous stage. The learning rate $\beta$ determines the magnitude of the correction term applied to adjust the weights of each neuron during training. The momentum $\alpha$ determines the lifetime of a correction term as the training process takes place, where high values of the momentum parameter will cause the network to retain more of the impact of previous corrections to the current corrections.

\section{Application of an ANN to Degradation Analysis of Cladding in Irradiated Fuel Pins}

The main cladding deformation mechanism in the fuel pins under consideration was established as irradiation creep under stresses from gas pressure loading and possibly fuel-cladding mechanical interaction (FCMI).[11] Up to the peak cladding temperature in this experiment, $560^{\circ} \mathrm{C}$, statistical analysis showed that thermal creep is not effective in HT-9.[12] This results in the following deformation correlation, which was the basis of the parametric bootstrap estimate of the probability distribution and its confidence interval discussed in the previous section.

$$
\begin{array}{rlr}
\epsilon & =A_{1} \dot{K} \overline{\mathrm{B}}^{2} \mathrm{~T}_{\mathrm{p}} & \left(\mathrm{B} \leq \mathrm{B}_{0}\right) \\
& =\mathrm{A}_{1} \dot{\mathrm{K}} \overline{\mathrm{B}}^{2} \mathrm{~T}_{\mathrm{p}}+\sqrt{\mathrm{A}_{2}\left(\overline{\left.\mathrm{B}-\mathrm{B}_{0}\right)+1}-1\right.} & \left(\mathrm{B}>\mathrm{B}_{0}\right)
\end{array}
$$


where

$\epsilon \quad=\quad$ clad strain,

$\overline{\mathrm{B}}=$ pin average burnup (at.\%),

$\mathrm{T}_{\mathrm{p}}=$ gas plenum temperature $(\mathrm{K})$,

$\dot{\mathrm{K}}=$ displacement per atom per second $\left(\mathrm{dpa} / \mathrm{s}^{*} 10^{7}\right)$

B $=$ local burnup (at.\%),
$\mathrm{A}_{1}=2.9 * 10^{-7}$,
$\mathrm{A}_{2}=0.54$,

and

$\mathrm{B}_{0} \quad=\quad 14.1$
\} Degradation measure

Computed fixed-effects variables

Estimated randomeffects parameters

This phenomenological correlation is parsimonious with respect to independent variables. Extensive calculations also showed that it is robust, in that the addition of more correlation parameters, such as local power density or clad temperature, does not improve the fit of the correlation.[11] The effectiveness of the correlation is demonstrated in Fig. 8, where the measured axial distribution of the clad strain is compared to the strain estimated by the above correlation, for different levels of burnup of two irradiated fuel pins. The upper curves correspond to data collected at higher burnups.

There are two drawbacks in the methodology associated with the use of this correlation. The first is the extent of the effort required to arrive at a model, much of it by trial and error. The second is that, when data begin to indicate that another degradation mode is becoming effective, it is likely that again an inordinate amount of analysis will be required to determine the form of the new degradation correlation. The application of ANN to the data is proposed to alleviate some of these difficulties. 

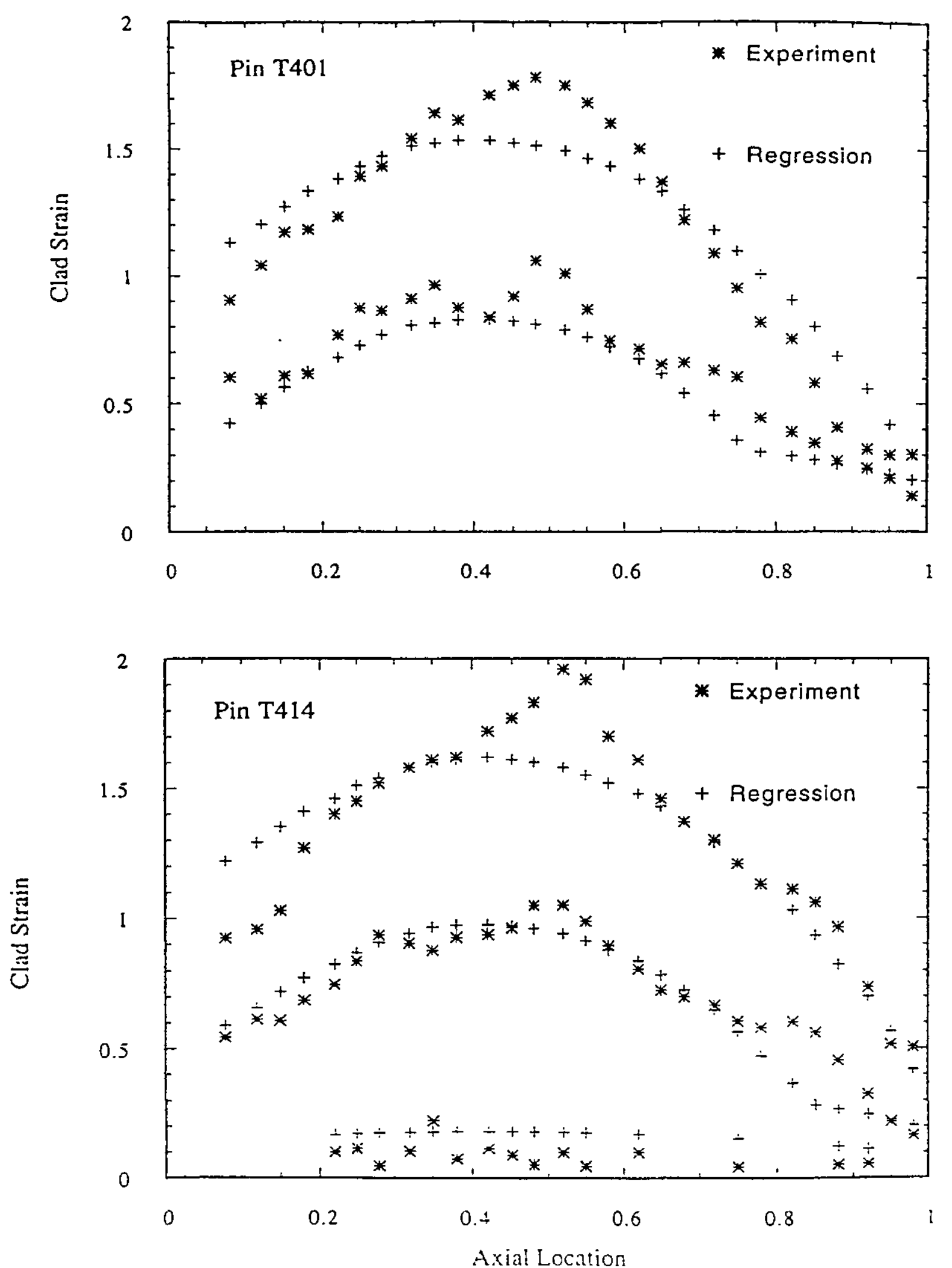

Fig. 8. Comparison of Measured Clad Strain to Regression Estimated Clad Strain 


\section{3a. Neural Network Training and Testing}

The data described in the previous section are also the data used in training the network. We validate the ANN by testing its ability to predict data which were not included in the training data. Two pins, T401 and T414, are selected to represent the testing data, and the remaining 17 pins comprise the training data. The two test pins were exposed to conditions that cover most of the range of the input parameters. Pin T414 was one of the few pins irradiated in row 5 of the subassembly, which made it experience a cladding temperature which is significantly different form the temperature experienced by the pins in $t$ he interior rows of the subassembly. This makes it a good candidate for testing the predictive power of the ANN. The cladding temperature was not included as an input parameter for its effect on clad strain in the range of temperatures in the experiment was shown to be negligible by classical statistical methods.[12] On the other hand, pin 401 was exposed to burnups, and has other irradiation parameters, that range over those experienced by the training pins.

\section{3a.1. The Neuralyst Program}

Neuralyst[13] is a user friendly, PC based, program which uses Microsoft Excel[14] spread sheet capabilities to perform neural network calculations. The data to be analyzed are loaded into an Excel spreadsheet. Neuralyst menus, which are additional to the usual Excel menus, are used to identify the input, target, and output parameters, and the training and testing data. The program allows the user to choose the network structure and parameters, such as the number of layers, the number of neurons in each layer, the learning rate, and the momentum. Also, the user is allowed to set limits on the amount of training through a training time limit or a training error limit. Another limit is the maximum number of epochs (where an epoch is a one pass through a cycle in which the training data are presented to the network, the error measure is estimated, and the weights are updated in such a way that the error is reduced).

The error estimate employed by the program is the root mean square error (RMS), which is given by 


$$
e_{R M S}=\sqrt{\frac{1}{n} \sum_{i=0}^{n-1}\left(t_{i}-o_{i}\right)^{2}}
$$

where $t_{i}$ is the target (true) value, $o_{i}$ is the value obtained by the network, and $n$ is the number of data points predicted by the network.

The program provides plots for both training and testing errors as a function of the number of epochs. An example is shown in Fig. 9. The root-mean-square error of the training data shows a steep descent early, and then attains a long term plateau, which indicates that the neural network has achieved as much learning as it can. A similar behavior is exhibited by the testing data. The root-mean-square error plot of the testing data is used to measure the point at which the neural network training was most successful on the testing data. As shown in the figure, the training data errors are usually smaller than the testing data errors.

\section{3a.2. Optimum Network Parameters and the Genetic Supervisor}

The neural network model includes certain parameters, such as the number of hidden layers, the number of neurons in each layer, and values for the momentum, and the learning rate. These cannot be determined a priori, and, thus, it is usually necessary to experiment with the characteristics of the network so as to establish the parameters which reduce the prediction error or the training time. This in effect brings us back to trial and error methods. The Neuralyst program, however, provides an option for optimizing these network characteristics by using a Genetic Supervisor. This program employs the genetic algorithm,[15] which consists of models of a selective evolutionary process which develops superior entities from a population of entities. The algorithm, used in the program, configures the best neural network that will train with the data, and adjusts the various parameters that control the network's optimum points. This in effect overcomes the drawback of manual trial and error testing of appropriate models. 


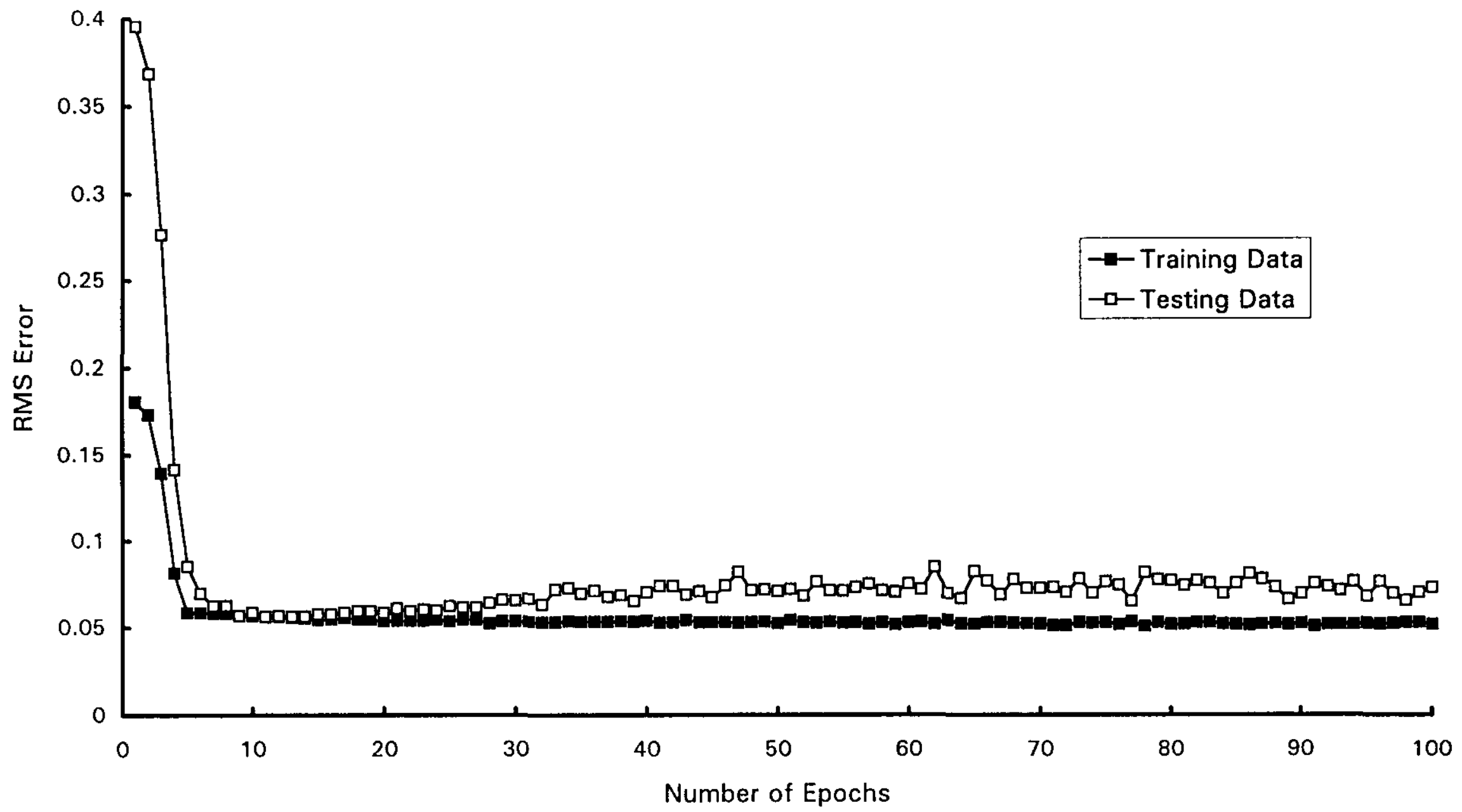

Fig. 9. Training and Testing Data Errors as a Function of the Number of Epochs 


\section{3b. ANN Estimates of the Degradation Data}

In order to get a feel for the results derived by the Genetic Supervisor, a network configuration was constructed via trial and error for the degradation data before applying the Genetic Supervisor. The initial guess for the configuration consisted of four hidden layers with five neurons per layer. The training and testing errors ranged, for most cases, between 0.2 to 0.3 , which is the RMS error described by Eq. (9). The errors leveled out after a relatively small number of epochs (usually less than 50). While training up to 1000 epochs, and using a large number of neurons per hidden layer, increased the training time orders of magnitude, it had only a relatively small effect on the training or testing errors. The simplest configuration, by trail and error, that was found to give a small error (about 0.196 for training and 0.198 for testing) was a 4 layer network with 2 hidden layers, which contained 6 neurons in the first hidden layer (closer to the input layer) and 3 neurons in the second hidden layer. A momentum value of 0.8 and 0.1 learning rate was used. A limit of maximum 50 epochs was considered sufficient for the training.

A comparison is shown in Fig. 10 between the target (measured) degradation data, the values predicted by the regression model, and the trial and error ANN predicted values, over the length of the two test pins. As in Fig. 8, the upper set of curves correspond to data collected at higher pin burnups. For both pins, the ANN estimates underpredict the strain at the higher burnups, while the generalization is better at the lower burnups. This is likely the result of the fact that the ANN can not recognize the change in the cladding behavior at higher burnups, where the FCMI becomes effective and starts to accelerate the degradation. The regression estimates, where this point is explicitly represented by the parameter $\mathrm{B}_{0}$, are better predictions at all stages of irradiation. The RMS regression error is 0.148 , compared to 0.196 and 0.198 for training and testing of the ANN, respectively. Figure 11 is another representation of the results, where the strain is plotted as a function of local burnups for different average pin burnups, irrespective of axial location. These show more clearly the deviation of the ANN estimated strain from the measured strain at high burnups, especially for pin T414. 

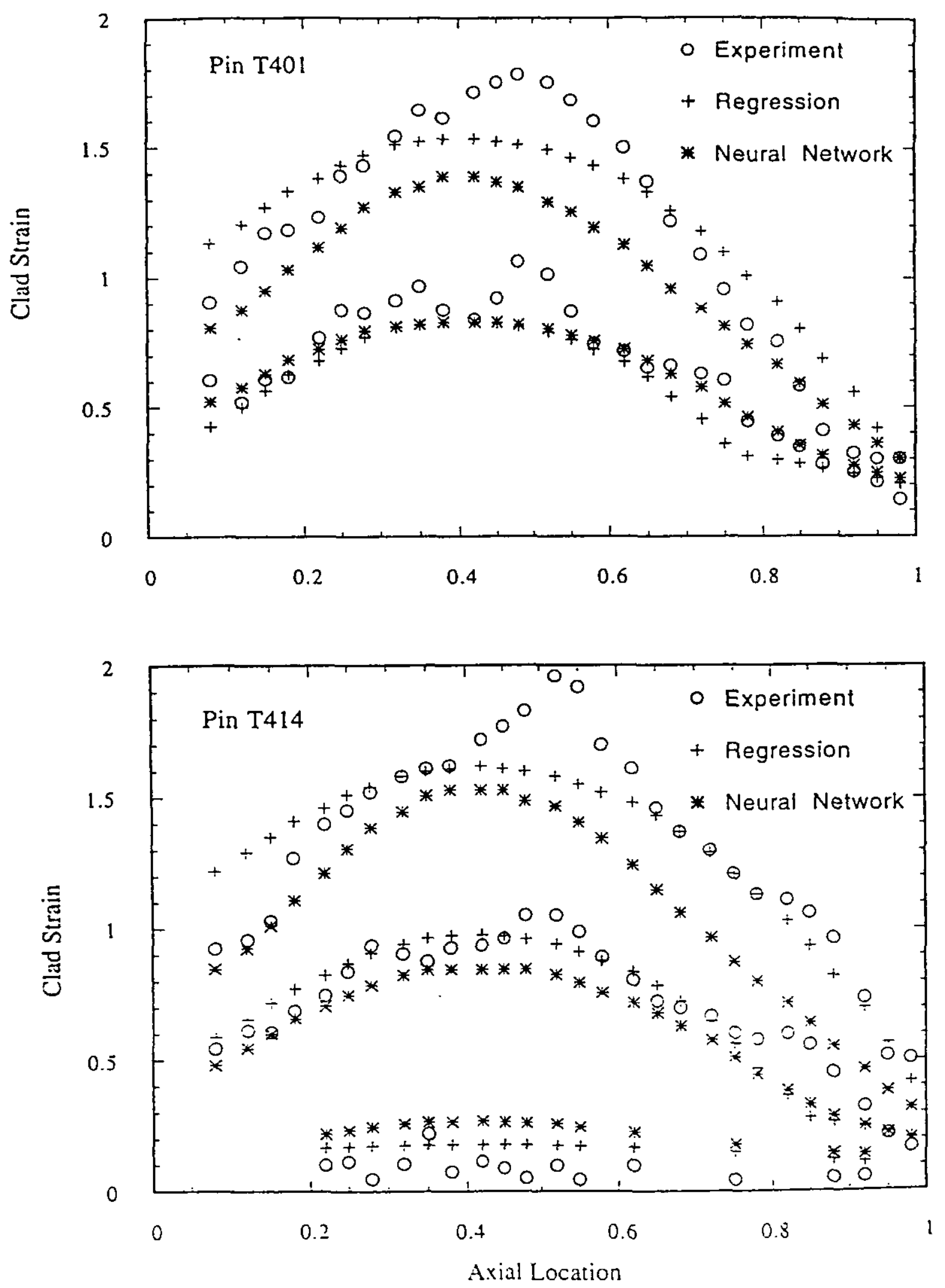

Fig. 10. Comparison of Measured Clad Strain, Regression, and ANN Estimated Clad Strain, as a Function of Axial Location (without ANN Genetic Optimization) 

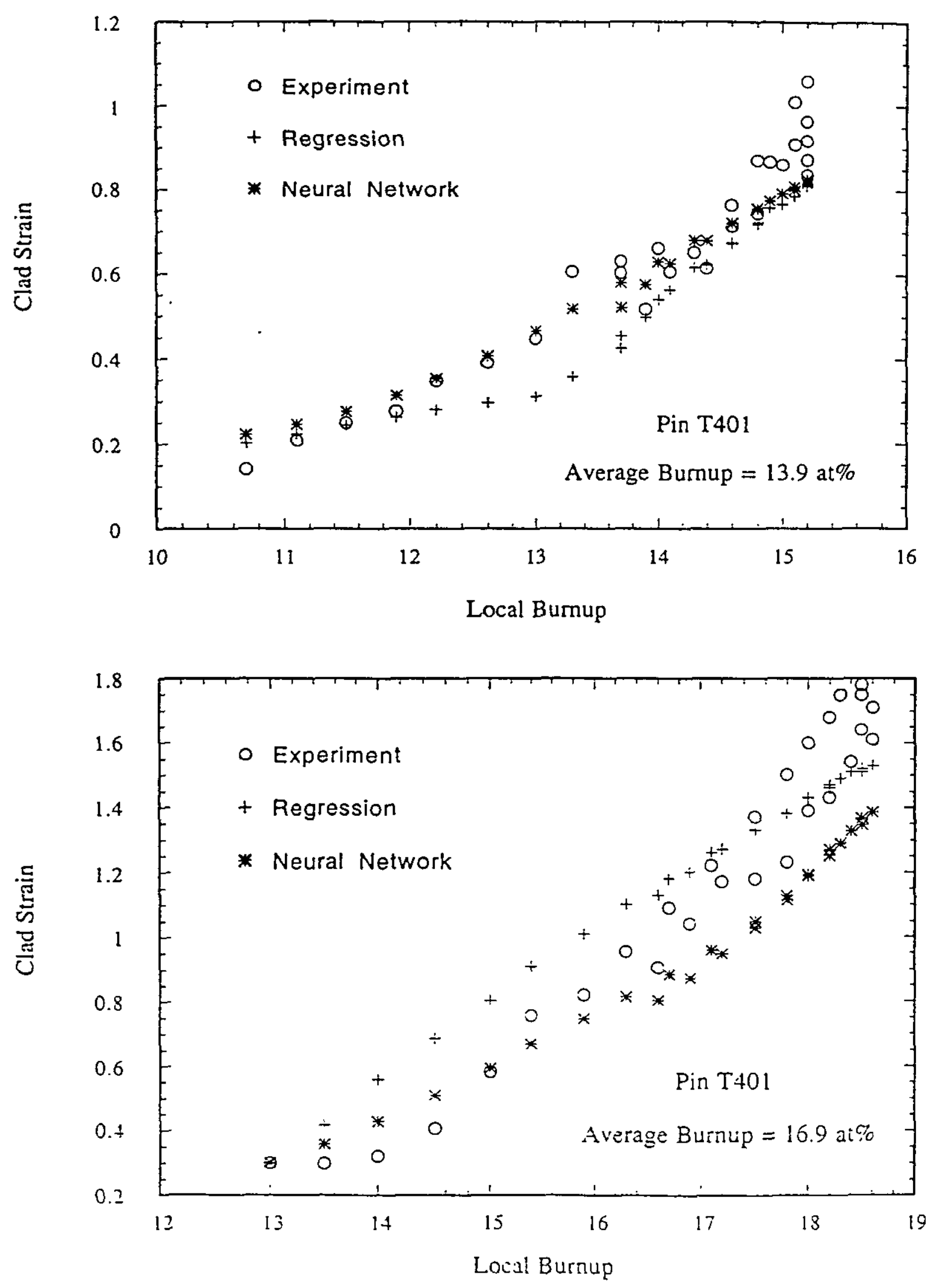

Fig. 11a. Comparison of Measured Clad Strain, Regression, and ANN Estimated Strain, as a Function of Local Burnup for Pin T401 (without ANN Genetic Optimization) 
$-26-$
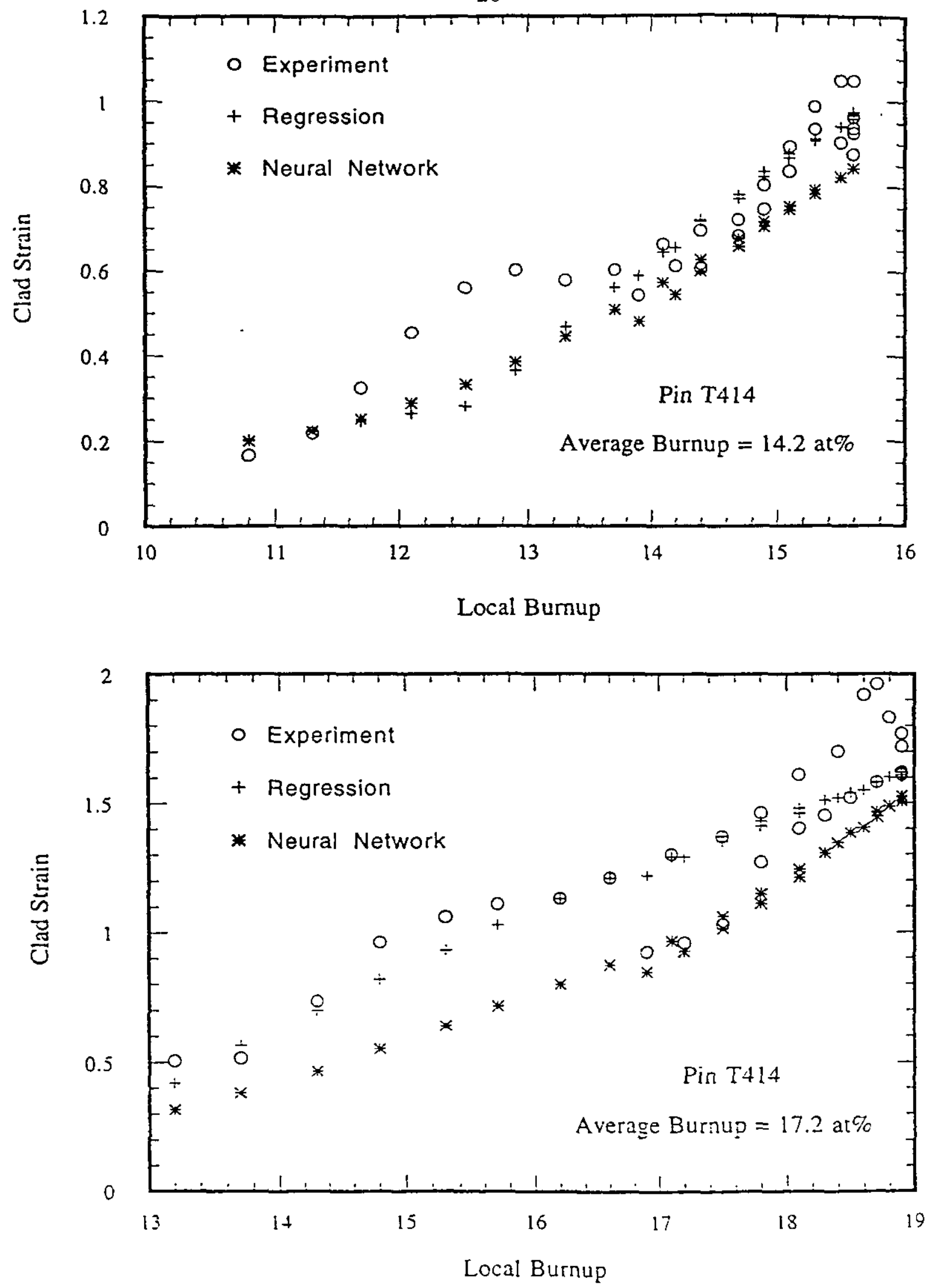

Fig. 11b. Comparison of Measured Clad Strain, Regression, and ANN Estimated Strain, as a Function of Local Burnup for Pin T414 (without ANN Genetic Optimization) 
The Genetic Supervisor was then used to obtain the optimum network configuration for the degradation data. The configuration selected by the Genetic Supervisor is shown in Table I. It consists of two hidden layers, as does the final trial and error configuration, but has more neurons per layer. In fact, the number of neurons per layer is greater than in the initial configuration, which led to the trial and error configuration. Figure 12a shows a comparison between measured strains, the strains predicted by the regression model, and the ANN predicted strains using the network configuration shown in Table I. The input noise parameter, shown in the table, is a number selected by the Genetic Supervisor, and provides a slight random variation to each input value for every training epoch. As training occurs, this has the effect of preventing the network from learning the exact input values, which prevents overtraining and improves the generalization process. The RMS errors are 0.15 and 0.17 for training and testing, respectively. This shows a significant improvement in the networks ability to predict the strain data, and the training error is quite close to the regression error. The figure shows the effect of the testing error reduction through a the better fit of the Genetic Supervisor's network over the fit in Fig. 10, especially at higher burnup. Similarly, Figs. $12 \mathrm{~b}$ and $12 \mathrm{c}$ show the improvement in fit, especially at higher burnups.

TABLE I. Genetic Supervisor Optimized ANN Configuration.

\begin{tabular}{||c|c|}
\hline Network Parameter & Value \\
\hline \hline Number of Layers & 4 \\
\hline No. of Neurons in the 1st Hidden Layer & 10 \\
\hline No. of Neurons in the 2nd Hidden Layer & 9 \\
\hline Learning Rate & 0.572 \\
\hline Momentum & 0.2166 \\
\hline Input Noise & 0.0216 \\
\hline Epochs & 100 \\
\hline
\end{tabular}



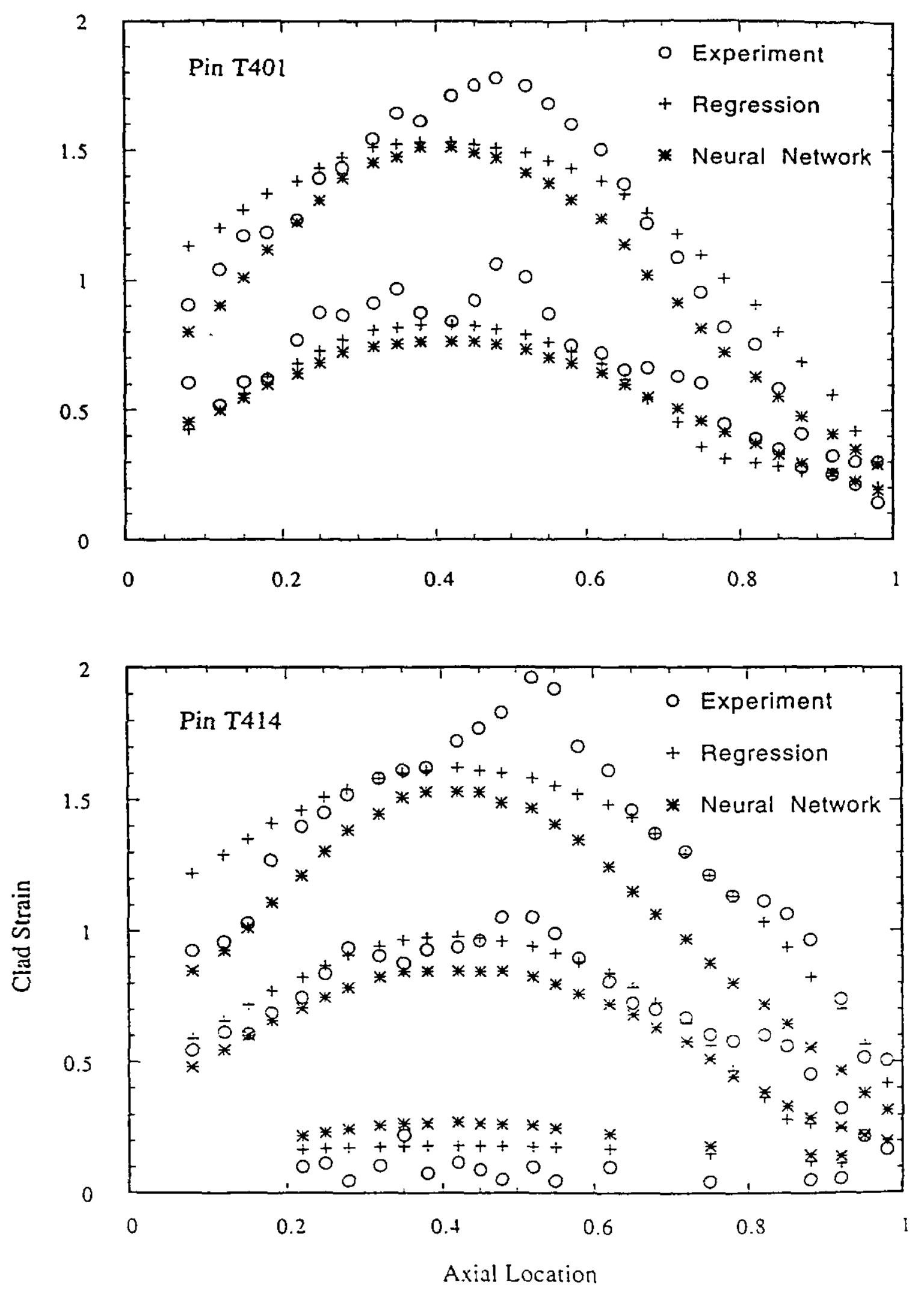

Fig. 12a. Comparison of Measured Clad Strain, Regression, and ANN Estimated Clad Strain, as a Function of Axial Location (with Ann Genetic Optimization) 

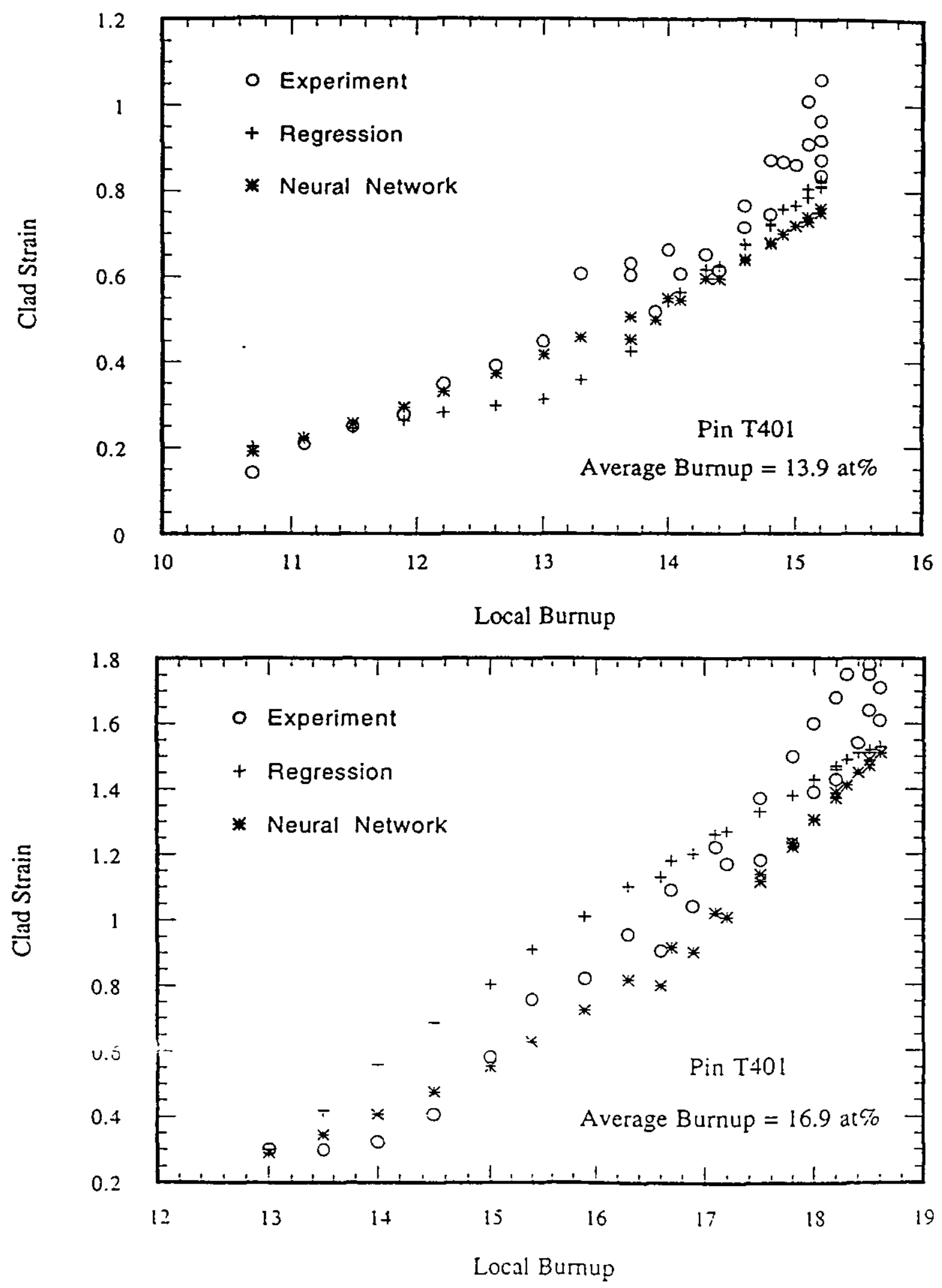

Fig. 12b. Comparison of Measured Clad Strain, Regression, and ANN Estimated Strain, as a Function of Local Burnup for Pin T401 (with ANN Genetic Optimization) 
$-30-$
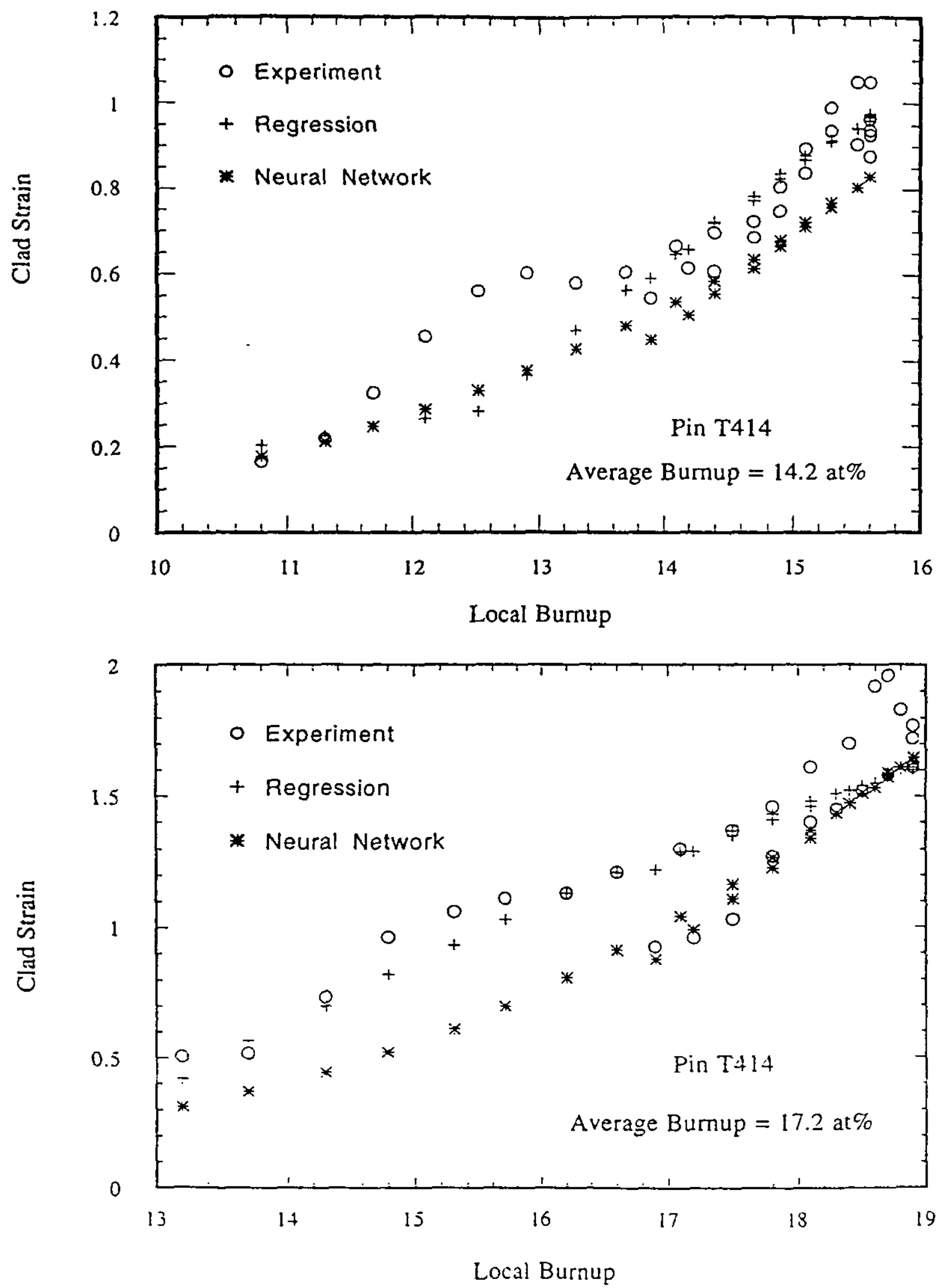

Fig. 12c. Comparison of Measured Clad Strain, Regression, and ANN Estimated Strain, as a Function of Local Burnup for Pin T414 (with ANN Genetic Optimization) 
The above comparison, although by no means definitive, does illustrate how the Genetic Supervisor can save considerable effort in achieving a good ANN representation of the degradation kinetics.

\section{CONCLUSIONS}

The degradation of the material in critical components is an effective measure which can contribute to the evaluation of the risk adjusted economic penalty associated with different maintenance decisions. The approach of estimating the probability, with confidence interval, of the time at which a proscribed degradation level of a particular component will be exceeded has been shown to be practical, as demonstrated in the analysis of irradiated fuel cladding. The methodology for the estimation of the probability is predicated on the existence of a parsimonious and robust mixed-effects model of the evolution of the degradation. The model explicitly accounts for the fact that degradation contains a stochastic component as well as a deterministic one. This model, in general, relates measured surrogates of the degradation level to computed or measured variables which characterize the environment during the operating history of the component. In this report we have proposed and demonstrated the efficacy of using an artificial neural network, constructed via a genetic supervisor, as a generally applicable laborsaving aid for developing the requisite mixed-effects model and testing its continued validity as new data are obtained.

\section{ACKNOWLEDGMENT}

The authors thank D. C. Wade for his insightful reading of the draft manuscript and his helpful comments. 


\section{REFERENCES}

1. H. Raiffa, "Decision Analysis," Addison-Wesley Publishing Company, Inc., 1968.

2. Proceedings: Utility Material Condition Monitoring Workshop, November 20-22, 1991, Palo Alto, CA, EPRI TR-101844.

3. A. M. Yacout, W. S. Yang, G. L. Hofman, and Y. Orechwa, "Average Irradiation Temperature for the Analysis of In-Pile Integral Measurements," Nuclear Technology, July 1996.

4. C. J. Lu and W. Q. Meeker, "Using Degradation Measurements to Estimate a Time-toFailure Distribution," Technometrics, 35:(2), May 1993.

5. A. M. Yacout, S. Salvatores, and Y. Orechwa, "Degradation Analysis Estimates of the Time-to-Failure Distribution of Irradiated Fuel Elements," Nuclear Technology, 113:(2), pp. 177-189, Feb. 1996.

6. I. B. Gertsbakh and Kh. B. Kordonskig, "Models of Failure," Springer-Verlag, New York, NY (1969).

7. W. S. Yang, P. J. Finck, and H. Khalil, "Reconstruction of Pin Power and Burnup Characteristics from Nodal Calculations in Hexagonal-Z Geometry," Nucl. Sci. Eng., 111:21-23 (1992).

8. K. L. Basehore and N. E. Todreas, SUPERENERGY-2: A Multiassembly, Steady-State Computer Code for LMFBR Core Thermal-Hydraulics Analysis," Pacific Northwest Laboratory Report, PNL-3379, C00-224557TR, August 1980.

9. A. Maren, C. Horston, R. Pop, "Handbook of Neural Computing Applications," Academic Press, San Diego, CA (1990).

10. P. Y. Werbos, "Beyond Regression: New Tools for Prediction and Analysis in the Behavioral Sciences," PhD Thesis, Harvard University (1974).

11. A. M. Yacout, S. Salvatores, and Y. Orechwa, "Database for Analysis of Advanced Reactors Fuel and Cladding Materials," Trans. Am. Nucl. Soc., 69:193, November 1993.

12. A. M. Yacout and Y. Orechwa, "Irradiation-Induced Creep of HT-9 Cladding of LMR Fuel Pins," Trans. Am. Nucl. Soc., 65:191, June 1992.

13. NEURALYST ${ }^{\mathrm{TM}}$, Cheshine Engineering Corporation, Pasadena, CA, (1994).

14. Microsoft EXCEL: User's Guide, Microsoft Corporation (1994). 
15. D. E. Goldberg, "Genetic Algorithms in Search, Optimization and Machine Learning," Addison-Wesley, Reading, MA, (1989). 
Distribution:
C. H. Adams
R. N. Hill
R. B. Turski
R. Agrawal
R. N. Hwang
R. B. Vilim
J. W. Ahrens
Kalimullah
D. C. Wade
J. C. Beitel
H. S. Khalil
D. K. Warinner
G. Birgersson
R. M. Lell
S. W. Wegerich
H. E. Bliss
H. Ley
R. N. Blomquist
J. J. R. Liaw
R. A. Wigeland
J. C. Braun
K. Laurin-Kovitz
A. M. Yacout
L. L. Briggs
R. D. McKnight
J. E. Cahalan
K. J. Miles
B. R. Chandler
E. E. Morris
L-K. Chang
M. B. Colosia
R. N. Nietert
Y. Orechwa
RA Division (15)
TIS Files
R. J. Cornella
G. Palmiotti
K. L. Derstine
K. E. Phillips
Y. I. Chang, OTD-ERD, 208
F. E. Dunn
P. A. Pizzica
J. Reifman
J. Roglans
E. E. Feldman
R. M. Singer
T. Sofu
J. J. Laidler, CMT, 205
E. K. Fujita
P. L. Garner
C. G. Stenberg
E. M. Gelbard
J. A. Stillman
K. N. Grimm
R. L. Surman
K. C. Gross
U. R. Hanebutte
T. A. Taiwo
L. W. Deitrich, RE, 208
D. R. Pedersen, RE, 208
D. P. Weber, RE, 208
J. P. Herzog
A. M. Tentner
B. J. ToppeI
M. J. Lineberry, TD ANL-W, 774
S. K. Bhattacharyya, TD, 207
H. F. McFarlane, TD ANL-W, 774
R. G. Bucher, TD, 207
D. J. Hill
L. C. Walters, ED ANL-W, 752
D. L. Porter, ED ANL-W, 752
H. P. Planchon, ED ANL-W, 752

\section{External Distribution for the ANL-FRA Report Series}

Office of International Nuclear Safety, NE-30, FORS

Office of Engineering and Technology Development, NE-50 GTN

Reactor Analysis Division Review Committee:

R. O. Anderson, Northern States Power Company, Minneapolis

M. L. Corradini, University of Wisconsin, Madison

A. F. Henry, Massachusetts Institute of Technology, Cambridge

J. C. Lee, University of Michigan, Ann Arbor

V. H. Ransom, Purdue University, West Lafayette

E. Lewis, Northwestern University, Evanston, IL (5)

W. F. Miller, Jr., Los Alamos National Laboratory, Los Alamos, NM

ANL-East Library

ANL-West Library

DOE-OSTI (2) - Office of Scientific and Technical Information
(Suokko)

(Franks) 